\title{
Factors affecting pre-visit destination image: application on the Grand Egyptian Museum (GEM)
}

\author{
Samia Adly Hanna El Sheikh \\ Faculty of Management Sciences, October University for Modern Sciences and \\ Arts (MSA), 6th of October City, Egypt
}

\begin{abstract}
Purpose - The purpose of this study is to investigate through an empirical research the factors that would attract visitors to heritage and cultural sites as museums applied on the Grand Egyptian Museum (GEM). The paper aims to study the impact of the proposed attraction features learning/knowledge, museum facilities, fun/entertainment and socializing and accessibility/location on pre-visit destination image.

Design/methodology/approach - The author started by a thorough literature review to arrive to the suggested conceptual model, which is tested by adopting a quantitative approach where data were collected using a self-administered questionnaire from a convenient sample of 300 respondents with $90 \%$ response rate and used partial least squares - structure equation modelling using Smart PLS v.3.2.8.

Findings - The results show that three of the tested factors were accepted and one was rejected.

Practical implications - Management of GEM, which will be one of the biggest museums world-wide, can make use of the empirical results of this research to enhance their understanding of the factors that impact pre-visit destination image, and thus, most attract visitors to justify the budget set in this huge project and achieve highest visitation and revenue

Originality/value - This research deals with a new museum that has not opened its doors yet and will start functioning in late 2020, and thus, the pre-visit image of the museum is not based on previous experience of visitors but rather on secondary sources as messages sent to visitors based on attraction features, while most previous studies dealt with post-visit image of museums
\end{abstract}

Keywords Partial least squares (PLS-SEM), Attraction factors to cultural destinations, Functions of a museum, Grand Egyptian Museum, Pre-visit destination image

Paper type Research paper

\section{Introduction}

Despite the fact that the Tourism sector in Egypt suffered from depression since the Egyptian revolution in 2011, the Egyptian Government has invested a huge sum to build the Grand Egyptian Museum (GEM) in a better and safer location as the old Egyptian museum suffered from damage and theft. The GEM will be one of the biggest museums world-wide and it is not only for the tourists coming to Egypt but also for all generations of Egyptians to handle down the heritage and protect the identity of Egypt. As such, the museum managers need to market for this project so as to attract the biggest number of both local and

(C) Samia Adly Hanna El Sheikh. Published in Journal of Humanities and Applied Social Sciences. Published by Emerald Publishing Limited. This article is published under the Creative Commons Attribution (CC BY 4.0) licence. Anyone may reproduce, distribute, translate and create derivative works of this article (for both commercial and non-commercial purposes), subject to full attribution to the original publication and authors. The full terms of this licence may be seen at http:// creativecommons.org/licences/by/4.0/legalcode

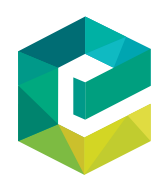


JHASS 2,3

international visitors, to maintain a sustainable source of income needed for the survival and maintenance of the museum services. According to the American Association of Museums (2012) at present museums are facing severe struggle due to very tough competition as they compete for a share of the customer's wallet not only with other cultural sites and monuments but also with other various types of leisure and entertainment activities such as cinemas, theatres, sports events, theme parks and other attraction events and outings (Heidenreich and Plaza, 2015). Added to this is the fact that governments are cutting down on budgets directed to cultural heritage sites when their people need more funds in areas that are more urgent and crucial as food, safety, health and basic education. In other words, museums are confronting a great pressure to attract more visitors to be able to support themselves especially in developing countries as Egypt.

This has led to an urgent need by museum managers to acquire a visitor-based role rather than a museum-based role (Sheng and Chen, 2012). This paradigm shift as per Del Chiappa et al. (2014) is a move from being product-oriented to consumer-oriented. Visitors or customers of a cultural destination represent the source of income that helps in the survival and further enhancement of the museum, which in this case could be considered as a business. Thus, destination managers have no other alternative but to attract visitors and more visitors to be able to maintain a sustainable source of income to further enhance the services of the destination. Moreover, governments and policy-makers need to formulate marketing strategies directed towards "increased visitation" and "repeat visitation". Thus, all interested groups should plan according to the factors that most attract visitors or "attraction features" that would most appeal to and attract the biggest number of visitors to justify the budgets placed into these projects or cultural destinations.

This study aims to investigate those attraction features that would create the best previsit mental image in the minds of visitors and to measure the impact of those attraction features on pre-visit destination image of domestic visitors towards the GEM, which logically would affect their intention to visit the museum. Moreover, success of those destinations to attract a big number of visitors will pay back and in turn will lead to an increase in the welfare of the community and the country as a whole. The value added of this research lies in the fact that up to the humble effort exerted by the author, all articles reviewed have dealt with the visitors' experience of already existing museums or other cultural destinations that handles partially or totally post-visit image; but this research is dealing with a new museum that has not opened its doors to the visitors yet and will start functioning in late 2020 or 2021, and thus this research deals with the pre-visit image of the museum, which will not be based on primary sources (previous experience of visitors to this specific destination) but rather on secondary sources of information messages sent by the destination through various media whether website or Facebook page or brochures or documentaries or press releases or advertisements about the GEM based on the attraction features that the management of GEM will use to attract visitors.

\section{The Grand Egyptian Museum}

Information about the GEM was collected by the author through the GEM's website. (http:// gem.gov.eg)

The GEM is one of the biggest projects undertaken by the Egyptian Government lately. This museum will be one of the biggest, if not the biggest museum world-wide. If the "old" Egyptian Museum received 317, 157 visitors in 2017 where the bigger percentage were international visitors and the number of visitors in the first five months of 2019 has reached 699,069 visitors both local and international (http://art-for-a-change.com/blog/2011/02/the-museum-at-the-centerof-egypts-revolution.html) Thus, the GEM should aim at a bigger number of visitors. 
The author also visited GEM page on Facebook. The number of followers on this Facebook page is 25,203 , which is not a large enough number to justify the importance of the project. There are many comments on the GEM Facebook page that indicate that Egyptian citizens support the GEM and encourage people to visit it once it opens its doors.

Application on the Grand Egyptian Museum

\subsection{The location of the museum}

The experts who worked on choosing this location for the GEM ensured that the location of the old museum was very unfortunate and extremely dangerous for the collection. The old Egyptian museum was located in Tahrir Square, which is the place that witnessed two recent revolutions in Egypt as Tahrir Square "liberty" square represents an icon where revolutionists, protestors and demonstrators gather to express their opinions and to demonstrate their request who sometimes get aggressive. Thus, a lot of damage has faced the old museum of Egypt (http://artfor-a-change.com/blog/2011/02/the-museum-at-the-center-of-egypts-revolution.html).

As such, the new museum had to go far away from downtown Cairo. The GEM is built on a site that is about $480,000 \mathrm{~m}^{2}$. It is located two $\mathrm{km}$ in the north direction of the Giza Pyramids on a sand hill (http://gem.gov.eg). Thus, the new location is important for the following reasons:

- The old location does not allow for any further expansion as it is tied up from all directions in a crowded downtown location.

- The new location is safer for both the visitors and the artifacts (collection)

- The new location is attractive as it is near the Pyramids, which are amongst the most important monuments of the world, and thus the new museum better fits with its historic surroundings.

\subsection{Phases of the museum}

The construction of the first and second phases were completed, which included the "restoration centre" and it comprised site-enabling activities and conservation and energy centres, a fire station and an artefact tunnel. The project construction is currently in its third phase. To be able to construct the museum in the selected site a site levelling task was undertaken in which an estimated 2.25 million $\mathrm{m}^{3}$ of sand was excavated and removed outside the museum site. This helped to maintain the view of the pyramids from the site (http://gem.gov.eg).

\subsection{The challenges that faced the Grand Egyptian Museum}

The main challenge that faced the construction of GEM was financing this museum and a negotiation and an agreement was made with Japanese Government and the UNESCO so, the Japanese Government funded a US\$300m loan and then they provided another loan, that is worth US $\$ 450 \mathrm{~m}$ to implement this huge project. So, the total cost or the total amount is US $\$ 750 \mathrm{~m}$. These loans will be returned to Japanese Government in long run with specific soft conditions (http://gem.gov.eg).

\subsection{The design of the museum}

The design of the museum resembles the pyramids. The entrance to the grand structure is one of the most striking features of the new museum as it will be a translucent stone wall, $800 \mathrm{~m}$ long, which is illuminated by the dramatic lighting schemes of the main building, this translucent wall will add night-time drama to the desert landscape (http://gem.gov.eg). 


\section{JHASS 2,3}

\subsection{Technological advances in the museum}

The new GEM is designed to include the latest technology, including virtual reality. A recent security system was installed to secure the monuments and the visitors and the lightening system used is LED as it provides cold lights that do not have any negative effect on the artifacts. Furthermore the museum will be a friendly place for people with special needs and disabilities (http://gem.gov.eg).

\section{8}

\subsection{The services in the museum}

Built over more than $480,000 \mathrm{~m}^{2}$, the museum will include exhibition galleries, a conference centre, retail areas and around 10 restaurants. It will also contain a 1,000-seat auditorium and three seminar rooms offering 250 seats, as well as gallery space, meeting rooms and a business centre. The museum will also consist of a permanent $24,000 \mathrm{~m}^{2}$ exhibition spaces, five galleries hosting the complete Tutankhamen collection and solar boat, an atrium with a Ramses II statue (http://gem.gov.eg).

\section{Theoretical background}

\subsection{Definition and functions (role) of a museum}

This study could be categorized to fall under the general topic of cultural and heritage tourism, which according to Brida et al. (2012) is a special type of interest based on seeking for and participating in cultural experiences. These experiences could be aesthetic, intellectual, emotional or psychological. This broad definition could incorporate many cultural forms as museums, festivals, historic sites, artistic performances, heritage sites and galleries. More specifically, the International Council of Museums (ICOM, 2007) gives a traditional definition of a museum as a non-for-profit organization that serves the society and opens its doors to the public. This institution's main task is to obtain, protect, conserve and exhibit the tangible and intangible historic heritage of human race to serve various purposes of education, enjoyment, economic and other.

According to Frey and Meier (2006) this definition lacks the effect of the economic environment in which a museum functions. Brida et al. (2012) add that museums like other business organizations can face commercial forces and that governments and policymakers regard museums as a source of revenue, which are required not only to cover up their own running expenses but also to incur extra budget to update and upgrade their facilities to attract more visitors that will further milk in revenue for the community.

Ahmad et al. (2014) agree with the International Museum Association that the function of a museum is not restricted to collect, preserve and store artifacts of heritage but also helps to handle down and protect the identity of a nation and to improve and enhance tourism industry and to spread knowledge to local people. Allan and Altal (2016) add to the attraction factors "escape", in the sense that people escape from their daily routine to a museum.

\subsection{Destination image}

According to Jin et al. (2013) destination image can be defined as the aggregation of a customer's beliefs, impressions and thoughts regarding a place or it is the overall idea created in the mind of the customers about the important characteristics of a destination. This overall idea may be influenced by different types of information about the site or is affected by emotional responses from previous visits to the same destination or other similar places.

According to Tan (2016), destination image is a complex blend of product, services and attributes intermingled together to form a total impression about the destination. The features or attributes of a destination involve a cognitive dimension that shapes a personal belief and mental image of the destination and an affective dimension, which is based on the 
cognitive dimension and it also relates to past feelings and emotions that the person could have experienced, not necessarily in the same destination but in any other destination, which helps the visitor recall the good times (Zhang et al., 2014). Thus, a visitor's previous experiences whether about the same destination or other will influence destination image, which, in turn, will influence visiting intension (Kim et al., 2012).

Destination image is a two dimensional construct that includes a cognitive/perceptive aspect and an affective aspect (Lu et al., 2015). The cognitive aspect is based on information and beliefs that the visitor has regarding the characteristics of destination at hand (Do Valle et al., 2012). This cognitive aspect has three parts, which are information about the services of the destination, the environment of the destination as the climate and cleanliness and finally the safety level of the destination. The affective aspect is based on the cognitive aspect and it could be related to previous experience of the destination or of similar destinations that include memory of good times and socializing with others and having fun (Prayag and Ryan, 2012). Wang and Hsu (2010) add that image is affected by any unique quality of the destination.

The visitor's experience which according to Mei (2007) is a complex personal psychological process that incorporates anything ranging from emotions, to intellect, aesthetic to nature, fun, amusement to socializing all together in a personalized way. According to Brida et al. (2013) there are push and pull motivational factors that affect the destination image and that attract the visitor's attention. Push factors are human and internal factors that can satisfy emotional needs, but pull factors are exterior factors, as special events and exhibits. Hosany and Prayag (2013) adopted a similar categorization of the attraction features or motivational factors into personal and situational characteristics; where each visitor goes to the museum carrying his personal characteristics, experiences, personal beliefs and personal goals on one hand and added to these are other situational factors that are related to the situation of the visit. Sheng and Chen (2012) state that visitors take the decision and choose to visit museum based on how they perceive the museum and the factors that went into building an image towards the museum. People differ from one another in their tastes and preferences, thus the more the factors of attraction available in the museum the more visitors will be attracted visit the museum.

Beerli and Martin (2004) conducted an interesting study on the analysis of the factors that create and influence destination image, in which they probe into the formation and structure of image. Here they differentiate between "first timers" and repeat visitors, where "first timers" base their image on secondary sources to which the visitor is exposed. These secondary sources include different agents that mingle together to produce one single image of the destination. These agents can be classified as follows:

- "overt sources" which is information coming from messages conducted by the destination.

- "covert sources" of information, which include using celebrities.

- Autonomous sources of information including documentaries and T.V. programmes and films about the place.

- Organic sources of information, which is information coming from friends and relatives in the form of word-of-mouth.

As for repeat visitors we add another fourth source, which is the experience of the visit or the primary source of information (Beerli and Martin, 2004).

As the author is dealing with "first timers" as the GEM has not opened yet, thus the image of future local visitors will depend on secondary sources based on information directed from the management of the GEM through their website, Facebook page, brochures, documentaries, news releases, celebrities or through any other media, the author set forth the following hypothesis: 


\subsection{The logical impact of positive image on intention to visit}

Destination image has a direct or indirect impact on intention to visit or to spread good word-of-mouth. A study conducted by Lu et al. (2015) on a historic destination in China proved the effect of image on most other marketing constructs as satisfaction and loyalty and intention to visit or to recommend a destination.

$\mathrm{Li}$ (2018) added that the visit experience is a systematic process that consists of before, during and after a visit, which points out the importance of predicting customer's expectations before visiting the museum to create positive mental image, and thus reinforce visiting intention as well as to enhance their interactions during the visit. $\mathrm{Li}$ (2018) and Liu and Idris (2018) emphasize that a person's mental image of the museum will finally affect the person's behaviour of visiting or not visiting the destination so it is of utmost importance to concentrate on all factors that affect building a person's mental image of the destination in question.

\subsection{Attraction features of museums}

Wang et al. (2012) found that attraction destinations, as museums, attract visitors by their cognitive, aesthetic and emotional roles in their study of three national parks in China and this is quite similar to the findings of other researchers as Kang and Gretzel (2012) who conducted a study on the National Park in Texas, USA and found that learning, enjoyment and escape are the basic attraction forces; where learning means that visitors acquire new skills and knowledge from their visit and enjoyment is the entertainment, fun and socializing and finally, escape is running away from everyday routine life to forget their daily responsibilities and problems. Dash and Samantary (2018) also adopted a similar categorization of attraction factors in cultural destinations of three categories; the first is education, which encompasses learning, knowledge of history, culture, heritage and values. The second category is fun, leisure, socializing and interest. The third category is aesthetics, which includes beauty and art. Su and Teng (2018) ensure that a museum visit is both cognitive in the sense of learning and gaining knowledge and affective, which emphasize that visitors have a social dimension, that is to be with friends, relatives or class mates, and thus to socialize and have fun as in Burton et al. (2009).

From the above the author set the following two hypotheses:

$H 2 a$. Learning, knowledge and education has a significant positive effect on the GEM image.

H2b. Fun and entertainment has a significant positive effect on the GEM image.

\subsection{The visitors' experience}

Many articles in the realm of museums and cultural destination marketing and management deal with the visitors' experiences to the destination. The visitors' experience is a multi-dimensional construct that covers all aspects of the visit among, which are the services rendered by the destination. The quality of the service is best measured by Parasuraman et al. (1988) original fivefactor measurement, that is used to measure quality of a service and these five factor measurements were studied in various service sector businesses as banking, appliance repair and maintenance centres and other. Moreover, some researchers, in the area of our concern, which is in museum services, also based their studies on the original SERVQUAL these researchers 
include but not restricted to Dash and Samantary (2018), Forgas-Coll et al. (2017), Kim et al. (2012), Brida et al. (2012), Rentschler and Gilmore (2002). Brida et al. (2016) state that the role of a museum is no longer restricted to the traditional role of collecting, preserving and exhibiting historic artifacts to support the value of knowledge as in the past, but that at present, a museum offers a wide range of other additional services that are both tangible and intangible that include but not restricted to organizing courses and seminars, printing brochures, selling history books from their bookshops, selling souvenirs from souvenir shops, food courts that help to serve and transmit pleasure to visitors and adds value to the visitors' experience.

Brida et al. (2016) stated that communication facilities of the service as the use of different languages and the facilities of offering explanations in different languages and the presence of an information centre that deals in different languages; and a constant effort to measure customers' (visitors) preferences and needs through surveys and other. Goulding (2006) highlights two important aspects in the visitors experience in her study conducted on Birmingham Museum and Art Gallery, the first of which is the methods of stimulating the interest and engagement as another dimension; and the second aspect is waiting time and queues, which again could be included under the facilities. Therefore, the author set another factor that affect visitors' image, which is museum facilities:

H2c. Museum facilities has a significant positive effect on the GEM image.

Some articles added another factor to the five original factors of SERVQUAL, which is the "location or ease of access" to the museum as transport facilities and road directions and parking lot. Bigne, Sanchez and Sanz (2009) stated that there is a functional component that affects visitors' image of a destination, which is location and accessibility to the destination through transportation. Moreover, Young-joo et al. (2016) in their study on 812 participants asking about the features that impact destination image and that attract visitors to come to cultural sites; the visitors mentioned that site accessibility/location to be the first of five and this incorporates that the site could be accessed easily by good traffic flow and has sufficient parking space and road guides or at least could be reached by means of transportation. Furthermore, Martin-Ruiz et al. (2010) also included location as a factor in their study of visitor's evaluation index.

Based on these studies and keeping in mind the advantages of the location of the GEM mentioned above, the author set forth the following hypothesis:

H2d. Location and accessibility has a significant positive effect on the GEM image.

\subsection{Categories of museum visitors}

Sheng and Chen (2012) stated that museum visitors are diverse and as such different types of visitors visit museums for different purposes and at different times. Hooper-Greenhill (2006) categorized visitors so that student groups tend to be the main visitors during working weekdays while children with parents are main visitors on the weekend. Moreover, tourists and tourist groups are the most common visitors in high touristic seasons. Tan (2016) divided visitors into two categories, namely, domestic and overseas where local visitors of students or families tend to repeat visitation more than overseas visitors. Local visitors tend to consider a re-visit or a second or third visit based on their experiences of previous visits or when they had missed to see or had seen very quickly parts of the collection or artefacts during previous visits or just to socialize. 
JHASS

2,3

222

4. Research questions, objectives and model

4.1 The research questions

RQ1. Do local potential visitors hold a positive image of the GEM?

$R Q 2$. Which attraction features have an impact on visitors' pre-visit destination image towards GEM, and thus motivates and attracts visitors to visit the GEM?

\subsection{The research objectives}

The main objectives of this research are to:

- Identify whether or not local domestic potential visitor have a positive image of GEM or not.

- Identify the attraction features that create the best mental image of GEM

\subsection{Research model}

From the above review of literature, the author suggested the following model: (Figure 1)

\section{The research design and methodology}

\subsection{The research approach}

The author started with secondary sources of information depending mainly on previous literature related to the topic in question and to a less extent on the website of the GEM and the Facebook page of the GEM to get a feel of locals' image of the GEM. The author adopted a quantitative approach and prepared a measurement tool (questionnaire), which includes seven sections dealing with the five main constructs of the research and the statements were taken and

\section{Attraction Features/ Dimensions}

Figure 1.

Conceptual model of the research

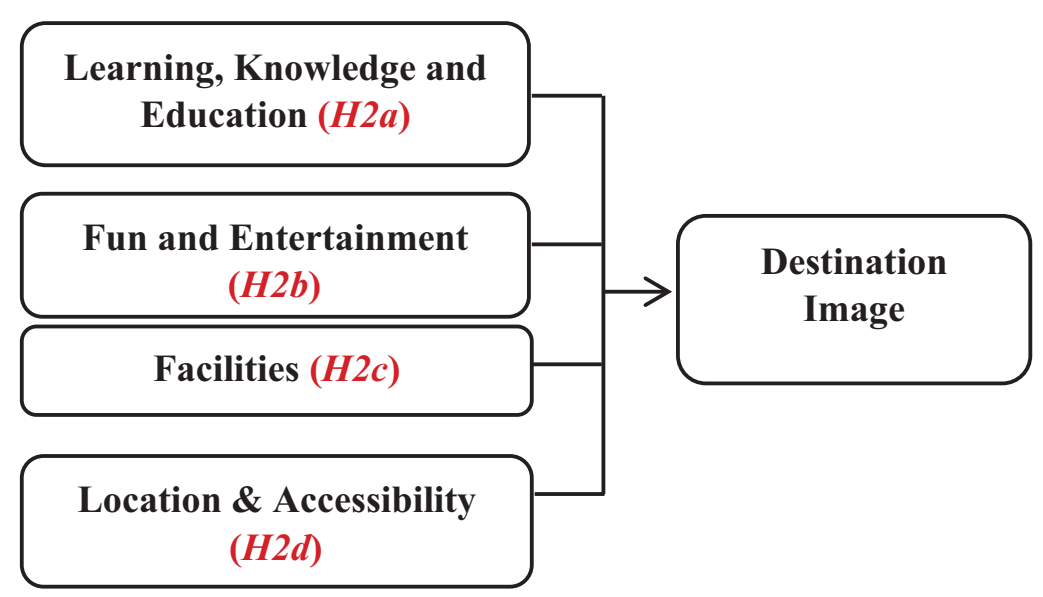


adapted from previous literature to ensure their validity and reliability; first construct, which is Learning, knowledge and Education mainly adapted from Ozel and Kozak (2012), Allan and Altal (2016), Tan (2016), Kang and Gretzel (2012), Ahmad et al. (2014), Baloglu and McCleary (1999), second construct Fun, entertainment and Socializing adapted from Jin et al. (2013), Beerli and Martin (2004), Kang and Gretzel (2012), Tan (2016), third construct Museum Facilities is mainly adapted from Chen et al. (2011), Camarero et al. (2011), Maher et al. (2011), the fourth construct Location and Accessibility adapted from Martin-Ruiz et al. (2010), Eusebio and Vieira (2011), the fifth construct Image adapted from Del Chiappa et al. (2014), Stern and Krakover (1993), a sixth the Grand section includes demographics of respondents and a seventh section on the source of secondary information about GEM and the respondents' intention to visit it once it opens.

\subsection{Research population and sampling}

5.2.1 Research population. The main population determined within the research is any local Egyptian or resident who is aware of the GEM. Thus, the first question of the questionnaire was a screening question: "Are you aware of the GEM?" and if the answer is "No" then the respondent was asked not to proceed and to give back the questionnaire.

5.2.2 Sample type and size. The sampling technique that the researcher used is nonprobability - convenience sampling. Non probability sampling is used because there is no access to the population frame. Convenience sampling is a type of non-probability sampling technique where subjects are selected because of their convenient accessibility and proximity to the researcher or because of the convenience of their volunteering, which helps to save time, effort and monetary resources, yet can offer practically useful information (Emerson, 2015). The author distributed 300 questionnaires (final form) and the response rate was almost $90.333 \%$ with 271 completed questionnaires.

5.2.3 Data collection process. The questionnaire was pre-tested before distributing the final form to the respondents. To pretest the data collection tool the researcher conducted 24 questionnaires in Arabic and English languages and amended some statements that the test respondents found slightly difficult to understand. Pilot testing is a small-scale trial, where a few examinees take the test and comment on any problems with the test instructions, instances where items are not clear and formatting and other typographical errors and/or issues that exist (Dikko, 2016). The final form of the questionnaire was distributed to the individuals who are aware of the GEM. The author collected data from two Governorates of Egypt, which are Giza and Cairo. The author approached places, which included clusters of people as clubs, malls and cafes near the old Egyptian museum or near the pyramids, which is the location of the GEM. The data collection process took almost a month and seven days starting from $17^{\text {th }}$ February till the $27^{\text {th }}$ of March 2019. The researcher faced some difficulties as many of those approached were not aware of the GEM, as such the data collection took longer than planned.

5.2.4 Sample characteristics. As can be seen from Table 1, the sample is almost balanced according to the respondent's gender, age, education level and occupation.

\section{Data analysis, results with discussion and explanation}

To analyse the proposed model, the author conducted a one sample $t$-test and descriptive statistics to analyse the image of GEM. Then, the author used the Partial least squares structure equation modelling (PLS-SEM) using Smart PLS v.3.2.8 (Ringle et al., 2015) to test the proposed conceptual model. 


\begin{tabular}{|c|c|c|c|}
\hline \multirow{2}{*}{$\begin{array}{l}\text { JHASS } \\
2,3\end{array}$} & Sample characteristics & Frequency & Valid (\%) \\
\hline & $\begin{array}{l}\text { Gender } \\
\text { Male } \\
\text { Female }\end{array}$ & $\begin{array}{l}143 \\
128\end{array}$ & $\begin{array}{l}52.8 \\
47.2\end{array}$ \\
\hline 224 & $\begin{array}{l}\text { Age } \\
18-26 \\
27-35 \\
36-44 \\
45-53 \\
\text { Over 53 years }\end{array}$ & $\begin{array}{l}77 \\
63 \\
51 \\
50 \\
30\end{array}$ & $\begin{array}{l}28.4 \\
23.2 \\
18.8 \\
18.5 \\
11.1\end{array}$ \\
\hline & $\begin{array}{l}\text { Educational level } \\
\text { High school degree (Thanaweya Amma or equivalent) } \\
\text { Bachelor degree } \\
\text { Master degree or } \mathrm{PhD} \\
\text { Other }\end{array}$ & $\begin{array}{r}62 \\
154 \\
51 \\
4\end{array}$ & $\begin{array}{r}22.9 \\
56.8 \\
18.8 \\
1.5\end{array}$ \\
\hline $\begin{array}{l}\text { Table 1. } \\
\text { Sample } \\
\text { characteristics }\end{array}$ & $\begin{array}{l}\text { Occupation } \\
\text { Student } \\
\text { Unemployed } \\
\text { Public sector employees } \\
\text { Private sector employees } \\
\text { Business owners } \\
\text { Others }\end{array}$ & $\begin{array}{r}62 \\
24 \\
27 \\
119 \\
30 \\
9\end{array}$ & $\begin{array}{r}22.9 \\
8.9 \\
10.0 \\
43.9 \\
11.0 \\
3.3\end{array}$ \\
\hline
\end{tabular}

\subsection{Gem image analysis}

To verify, the positive image of the GEM, that is to test $H 1$, the author used a One Sample $t$-test as can be seen in Table 2. The GEM image is composed of the average of all the four items of the image. In addition, one sample $t$-test aims at comparing the observed mean from the sample with a standard value or a benchmark. In this study, the researcher used 3 as a standard value to test the significant difference of the observed mean of image from the neutral value 3 in Likert type scale where (1) is strongly disagree to (5), which is strongly agree.

As can be seen from Table 2, the sample has a positive image mean by 4.4 out of 5 point on Likert scale. This positive image has a significant difference from the neutral value 3 of 5 on the same scale at confidence level $99.9 \%$. Therefore, $H 1$ is supported.

Next, Table 3 shows the multi response items of the main sources of information about GEM.

Table 3 points out that the main source of information about the GEM is the Social media by $39 \%$, which is consistent with the social media use by the demographic characteristics of the sample, this is followed by the relatives and friends who represent $26 \%$, which means the GEM talk takes place in family/friends gathering. Next in line source is the news and releases by $14.7 \%$. All of these three main sources reflect how people got to know about the project and the most important information sources.

Logically, the positive image of the GEM results in the positive intention of visiting GEM when it opens and this can be seen in Table 4 found below. This goes hand in hand with the positive image of the GEM found in Table 2.

Table 2.

One sample $t$-test results of the GEM image

\begin{tabular}{lcccccccc}
\hline Variable & $N$ & Mean & SD & Test value & $t$ & df & Sig. (two-tailed) & Mean difference \\
\hline Image & 268 & 4.401 & 0.563 & 3 & 40.741 & 267 & 0.000 & 1.401
\end{tabular}


A PLS-SEM approach has been adopted, as the current study aims at exploring new relationships based on the prior literature to extend on it. PLS-SEM gains its widespread use across different disciplines as Hair et al. (2012) report its important use in marketing and Usakli and Kucukergin (2018), Ali et al. (2018), Do Valle and Assaker (2016) reviewed its use in hospitality and tourism industry.

Before proceeding with the SEM, the author reports the descriptive statistics of the measurement items of the study variables. As in Table 5, the study variables' indicators have high means ranging from 3.71 to 4.68 out of five-point Likert scale where (1) reflect totally disagree and (5) reflects totally agree. Therefore, there is a preliminary indication of the acceptance on both the independent and dependent variables. Furthermore, the standard deviation has positive low coefficients, which indicate normal dispersion distribution around the mean. Finally, each one of the measurement items data violates the normality assumptions. Where the skewness should equal to the Kurtosis equal to zero, none of the measurements match this criterion. However, the violation of the normality in each of the measurement items has no serious effect on the results when the skewness coefficient ranges from $(-3:+3)$ and the kurtosis coefficient ranges from $(-20:+20)$. Therefore, the violation of the normality has no significant effect on the statistical analysis results (Kline, 2015; Pallant, 2011). Moreover, the PLS -SEM is a non-parametric analysis that can analyse non-normally distributed data with no problem (Hair et al., 2011). Thus, the researcher can proceed with the PLS-SEM.

Using the Smart PLS v.3.2.8, the author applied the PLS-SEM (Ringle et al., 2015). Following the systematic two-stage approach in building SEM, the researcher aims at developing the measurement model at the first stage, while testing the proposed relationships in the structural model is the main objective at the second stage (Hair et al., 2014, 2016).The first stage results of the measurement model are shown in Table 5. The measurement model is assessed in three main steps (Hair et al., 2014, 2016). First, the indicator reliability must be at least 0.4 and preferably higher than 0.708. If an indicator has low loading, the other high loadings' items at the same construct can substitute it. All of the indicators are higher than 0.708 except Image 1, Knowledge 3, Entertainment 2 and Entertainment 3. However, the decrease in those items' loadings can be substituted by the increase of the other items at the same constructs. Second, the convergent validity of each construct should be higher than 0.5 , which is the case as in Table 5 . Moreover, the

\begin{tabular}{lrr}
\hline & & Responses \\
Attributes & $N$ & $(\%)$ \\
\hline Social media & 165 & 39.0 \\
Relatives/friends & 110 & 26.0 \\
news and releases & 62 & 14.7 \\
Others (please specify) & 50 & 11.8 \\
Advertisements & 36 & 8.5 \\
Total & 423 & 100.0
\end{tabular}

Note: Respondents could select more than one option in this section of the questionnaire

Application on the Grand Egyptian Museum

225 $-$ 
JHASS

2,3

226
Table 5.

Measurement model and study variables descriptive statistics

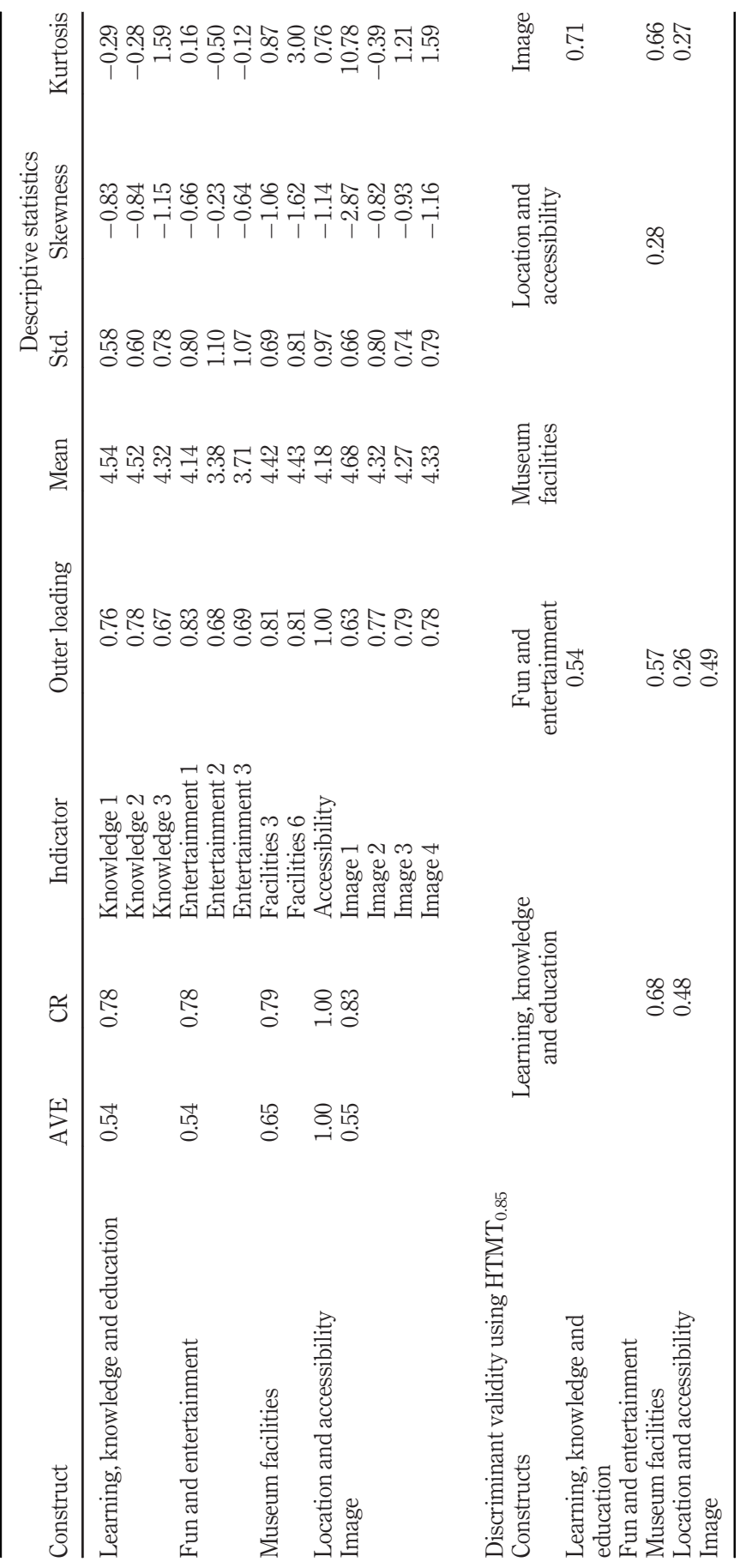


discriminant validity between constructs should be assessed using Heterotrait-Monotrait (HTMT) (Henseler et al., 2015). As in Table 5, the HTMT between each pair of constructs is below 0.85 , then the discriminant validity between the constructs has been established. Third, to test the internal consistency, the common test is the Cronbach's alpha. However, the author fears its shortcoming especially in SEM; as it is significantly affected by the number of indicators, the Cronbach's alpha will be higher than 0.7 if the construct has 10 indicators even if some of these indicators are not valid (Pallant, 2011). In this concern, researcher investigates depending on the composite reliability (CR) as it is more accurate than the traditional Cronbach's alpha especially in SEM (Hair et al., 2010). Therefore, as lowest construct CR is 0.78, which is higher than the threshold 0.7, the model constructs' reliability is established as well.

In regard to testing structural model in multi criteria; first, the multi-collinearity between the exogenous (independent) variables should be eliminated using variance inflation factor (VIF). As in Table 6, the VIF between the exogenous variables ranges between 1.2 and 1.35, which is within the proposed range (0.2:5). This indicates that the multi-collinearity in this study is not an issue (Hair et al., 2014).

Second, the path coefficient for each relationship should be significant at confidence level $95 \%$. Using bootstrapping procedure of 5000 subsamples with 300 iterations, the results of path coefficients are shown in Table 6. In this regard, the learning and knowledge has a significant positive effect on the GEM image by $31.3 \%$ at confidence level $99.9 \%$. Therefore, H2a is supported. Additionally, fun and entertainment has a significant positive effect on the GEM image by $17.4 \%$ at confidence level $99 \%$. Therefore, H2b is supported. Next, the museum facilities have a significant positive effect on the GEM image by $21.3 \%$ at confidence level $99.9 \%$. Therefore, H2c is supported. Finally, the location and the accessibility have a non-significant positive effect on the GEM image by $3.9 \%$ at confidence level $99 \%$. Therefore, H2d is not supported.

Finally, the predictive ability should be assessed via three criteria (Assaf and Tsionas, 2019; Hair et al., 2014; Shmueli et al., 2019). First coefficient of determination to assess the dependent variable predictive power using $R^{2}$; where $R^{2}$ coefficient $0.25,0.5$ and 0.75 indicate weak, moderate and strong predictive power consecutively. As in Table 6, the GEM image variance is $R^{2}=30.3 \%$. This indicates moderate explanation factor of the GEM image. Moreover, the blindfolding procedure to assess the dependent variable predictive relevance using $\mathrm{Q}^{2}$; where $\mathrm{Q}^{2}$ coefficient $0.02,0.15$ and 0.35 indicates weak, moderate and strong predictive relevance. As in Table 6, using omission distance $\mathrm{D}=7$, the GEM image has a predictive relevance $\mathrm{Q}^{2}=15.1 \%$, which indicate moderate predictive relevance.

The research model with results (Figure 2 ).

\section{General conclusion}

In conclusion, from the path analysis it can be seen that local domestic potential visitors do hold a positive image of the GEM and, as this study is based on the premise that "image"

\begin{tabular}{lrrrrr}
\hline Path & & VIF & $\beta$ & $t$-value & $p$-values \\
\hline$H 2 a$ & Learning, knowledge and education - > image & 1.351 & 0.313 & 4.979 & 0.000 \\
$H 2 b$ & Fun and entertainment - > image & 1.240 & 0.174 & 2.751 & 0.006 \\
$H 2 c$ & Museum facilities - > image & 1.208 & 0.213 & 3.265 & 0.001 \\
$H 2 d$ & Location and accessibility - > image & 1.173 & 0.039 & 0.658 & 0.511
\end{tabular}

Note: $R^{2} 0.303, Q^{2}=15.1 \%$

Table 6. Structural model 


\section{JHASS \\ 2,3}

228

\section{Figure 2.}

Research model with structural results

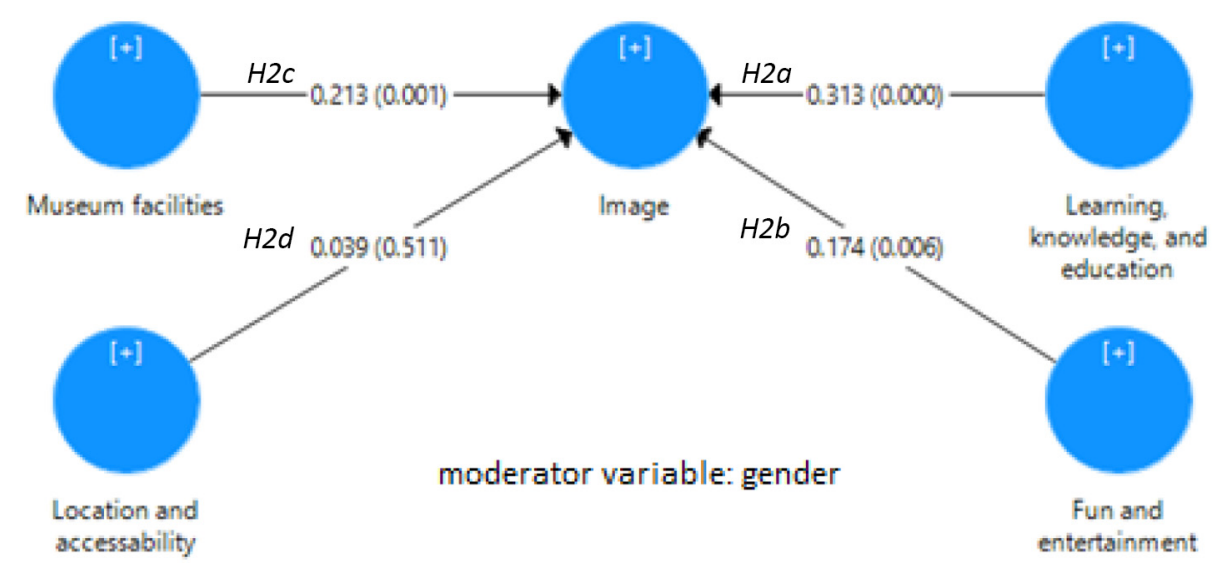

Plays an important role in the marketing of services. In Li (2018), Liu and Idris (2018) Lu et al. (2015) a visitor's mental image of a museum will affect the intention to visit the museum:

- As the author is dealing with "first time" visitors to GEM, thus the factors that impact pre-visit image are very important and as such following:

- Learning/knowledge has a significant positive effect on the image of GEM and this goes hand in hand with previous literature as in Dash and Samantary (2018), Kang and Gretzel (2012) and Brida et al. (2016).

- Fun/entertainment/socializing has a significant positive effect on the image of GEM and this agrees with previous literature in Burton et al. (2009) and Dash and Samantary (2018).

- Museum facilities have a significant effect on the GEM image and this agrees with several previous studies as Brida et al. (2016), Martella et al. (2017) and Ahmad et al. (2014).

- Location/accessibility does not impact GEM's image but this is contrary to literature as in Bigne, Sanchez and Sanz (2009), Young-joo et al. (2016) and Martin-Ruiz et al. (2010).

\subsection{Theoretical implications}

This study has theoretical and practical implications. From a theoretical standpoint the conceptual model developed and tested by the author about the determinants of destination image added to the previous knowledge by further enhancing the understanding of image in regard to probing into pre-visit image rather than post-visit image where previous visitation experience plays no role. In this sense, the author shed some light on image theory by empirically proving the factors that influence pre-visit image.

\subsection{Managerial/practical implications}

From a practical managerial point of view, the study gives guidance to destination marketers that pre-visit image, which is affected by secondary sources, and thus information sent out to visitors should deal with the attraction features that influence image 
and that are important to future visitors. In addition, the study also directs some practical messages to the GEM management in specific as follows:

- Many of the local people are unaware of the GEM, so management needs to work on higher awareness of the people of the grand new project. Awareness could be done through mass media channels as TV talk shows, radio advertisements, which could be quite expensive and a less expensive option is through social media in the form of brand ambassador celebrities who could be football players or famous stars who could put their photos in the GEM on Facebook or Instagram. These celebrities have the Grand thousands of followers, and thus awareness of the destination will increase, As in Beerli and Martin (2004) secondary sources of information that help to create previsit destination image include the use of celebrities and documentaries and T.V. programmes, talk shows, which can all be uploaded on the website of GEM to further attract visitors and can be way less expensive than direct advertisements.

- Moreover, from the research results it is clear that the main source of information about GEM was through Social Media (39\%) this sends another signal to GEM's management to emphasize the importance of the museum's website that has to give the best possible information and to try and make it more interactive to visitors, to answer queries and respond to any questions.

- From the results of the study, GEM's managers should pay special care towards those facilities of the museum that enhance knowledge and learning as advanced display screens that allow for accurate information, mobile applications that function within the museum that are interactive and allow visitors to ask and get information at their own pace, as this allows more engagement and the use of various languages that ensures even higher engagement, which leads to better learning and as according to El Sheikh (2019) engaged customers undertake favourable required outcomes of trust, future patronage, good word of mouth, which are necessary for increased visitation.

- Moreover, some museums have a child museum that facilitates learning for young children and allow them fun at the same time with simplified explanations of history that allow school students a sense of belonging and ensure that they identify with their history and heritage. This is done through a combination of techniques that allow visitors to move along the story of history where each epoch unfolds after the previous that helps the younger children or youth to learn easily.

- In addition, destination managers are highly encouraged to develop strategies that improve social interaction and that enhance fun and socialization as cafes, restaurants that allow for socialization to ensure a positive visitors' experience. Furthermore, some destinations create attraction by combining imagination with reality as in fear rooms where stories of past secrets are re-incarnated to set forth fear emotions that greatly appeal to youth as "the Dungeons" in London. This could be replicated using the curses and the secrets of the "Pharos".

- Finally, souvenir shops also attract visitors to carry back a memory of the visit that would encourage them to re-visit GEM, which will lead to higher income, and thus achieve the required goal of increased visitation.

\section{Limitations and suggestions for further research}

The research has the common serious limitation that arises from sampling type (convenience), which makes generalizations hazardous. There are also the limitations of time, effort and expenses that face research in general. 
JHASS 2,3

The researcher invites further research as follows:

- Sheng and Chen (2012) suggest that visitors' experience is not static but a dynamic process, which incorporates the visitor's experiences before, during and after the visit. It goes without saying that once the GEM opens its doors to visitors a suggested further research is to measure visitors' satisfaction with the experience using SERVQUAL as Maher et al. (2011) reinvestigated the dimensions of service quality in museum sector to see if it can be successfully applied in the sector. Thus, it can be used to examine the relationship between the quality of service offered and the repeat visit to the museum.

- Moreover, as Beerli and Martin (2004) had mentioned that destination image is affected not only by the information directed towards the visitors but also by the internal characteristic factors as preferences and other personal factors and sociodemographic factors as age, gender and level of education, the author suggests investigation into the impact of these socio demographic variables and their impact on destination image and intention to visit of the GEM.

- Moreover, the authenticity of the destination has an impact to attract visitors to the destination. Authenticity plays a crucial role to influence visitors of heritage destination. Beverland and Farrelly (2010) suggest that authenticity is a "state of mind" of the visitor. Thus, perceived authenticity is more important than actual authenticity. As such, authenticity is another construct that could be further investigated.

- In addition, the suggested model in this research could be future tested on other destinations in Egypt as theme parks, new cities and cultural destinations especially that the present Egyptian Government is undertaking many new attraction destination projects that align with Egypt's vision 2030 to attract more tourists to visit the country.

- Finally, the model could be taken one step further to include the impact of destination image on other marketing constructs as loyalty in the form of repeat visitation or positive word of mouth.

\section{References}

Ahmad, S., Abbas, M., Taib, M. and Masri, M. (2014), "Museum exhibition design: communication of meaning and the shaping of knowledge", Procedia - Social and Behavioral Sciences, Vol. 153, pp. 254-265, available at: www.sciencedirect.com (accessed August 2018).

Ali, F., Rasoolimanesh, S.M., Sarstedt, M., Ringle, C.M. and Ryu, K. (2018), "An assessment of the use of partial least squares structural equation modeling (PLS-SEM) in hospitality research", International Journal of Contemporary Hospitality Management, Vol. 30 No. 1, pp. 514-538.

Allan, M. and Altal, Y. (2016), "Museums and tourism: visitors motivations and emotional involvement", Mediterranean Archaeology and Archaeometry, Vol. 16 No. 3, pp. 43-50.

Assaf, A. and Tsionas, M. (2019), "Quantitative research in tourism and hospitality: an agenda for bestpractice recommendations", International Journal of Contemporary Hospitality Management, Vol. 31 No. 7, pp. 2776-2787, doi: 10.1108/IJCHM-02-2019-0148.

Baloglu, S. and McCleary, K. (1999), "A model of destination image formation”, Annals of Tourism Research, Vol. 26 No. 4, pp. 868-897.

Beerli, A. and Martin, J. (2004), "Factors influencing destination image", Annals of Tourism Research, Vol. 31 No. 3, pp. 657-681, available at: www.elsevier.com (accessed August 2018).

Beverland, M.B. and Farrelly, F.J. (2010), "The quest for authenticity in consumption: consumers' purpositive choice of authentic cues to shape experienced outcomes", Journal of Consumer Research, Vol. 36 No. 5, pp. 715-723. 
Bigné, E., Sańchez, I. and Sanz, S. (2009), "The functional-psychological continuum in the cognitive image of a destination: a confirmatory analysis”, Tourism Management, Vol. 30 No. 5, pp. 715-723.

Brida, J.G., Disegna, M. and Scuderi, R. (2013), "Visitors of two types of museums: a segmentation study", Expert Systems with Applications, Vol. 40 No. 6, p. 2225.

Brida, J., Meleddu, M. and Pulina, M. (2016), "Understanding museum visitors' experience: a comparative study", Journal of Cultural Heritage Management and Sustainable Development, Vol. 6 No. 1, pp. 47-71.

Brida, J., Pulina, M. and Riano, E. (2012), "Measuring visitor experiences at a modern art museum and linkages to the destination community", Journal of Heritage Tourism, Vol. 7 No. 4, pp. 285-299.

Burton, C., Louviere, J. and Young, L. (2009), "Retaining the visitor enhancing the experience: identifying attributes of choice in repeat museum visitation", International Journal of Nonprofit and Voluntary Sector Marketing, Vol. 14 No. 1, pp. 21-34.

Camarero, C., Garrido, M.J. and Vicente, E. (2011), "How cultural organizations' size and funding influence innovation and performance: the case of museums", Journal of Cultural Economics, Vol. 35 No. 4, pp. 247-266.

Chen, C., Lee, H., Chen, S. and Huang, T. (2011), "Tourist behavioral intentions in relation to service quality and customer satisfaction in Kinmen National Park, Taiwan”, International Journal of Tourism Research, Vol. 13 No. 5, pp. 416-432.

Dash, P. and Samantary, M. (2018), "Exploring determinants of a successful tourism experience- the Nabaka Lebara event", International Journal of Event and Festival Management, Vol. 9 No. 1, pp. 104-119, doi: 10.1108/IJEFM-06-2017-0039 (accessed August 2018).

Del Chiappa, G., Andreu, L. and Gallarza, M. (2014), "Emotions and visitor's satisfaction at a museum”, International Journal of Culture, Tourism and Hospitality Research, Vol. 8 No. 4, pp. 420-431.

Dikko, M. (2016), "Establishing construct validity and reliability: Pilot testing of a qualitative interview for research in Takaful (Islamic insurance)", The Qualitative Report, Vol. 21 No. 3, pp. 521-528.

Do Valle, P.O. and Assaker, G. (2016), "Using partial least squares structural equation modeling in tourism research: a review of past research and recommendations for future applications", Journal of Travel Research, Vol. 55 No. 6, pp. 695-708.

Do Valle, P.O., Mendes, J. and Guerreiro, M. (2012), "Residents' participation in events, events image, and destination image: a correspondence analysis", Journal of Travel and Tourism Marketing, Vol. 29 No. 7, pp. 647-664.

El Sheikh, S. (2019), "How engaged customers can help the brand: an empirical case study on a higher education institution (university) in Egypt", International Journal of Marketing Studies, Vol. 11 No. 1, pp. 85-99.

Emerson, R.W. (2015), "Convenience sampling, random sampling, and snowball sampling: how does sampling affect the validity of research?”, Journal of Visual Impairment and Blindness, Vol. 109 No. 2, pp. 164-180.

Eusebio, C. and Vieira, A. (2011), "Destination attribute evaluation, satisfaction and behavioral intentions: a structural modeling approach", International Journal of Tourism Research, Vol. 15 No. 1, pp. 66-80, doi: 1002/jtr.877. (accessed August 2018).

Forgas-Coll, S., Samuel, R., Malute, J. and Tarrega, S. (2017), "How do service quality, experiences and enduring involvement influence tourists behavior? An empirical study in the Picasso and Miro museums in Barcelona”, International Journal of Tourism Research, Vol. 19 No. 2, pp. 246-256.

Frey, B.S. and Meier, S. (2006), "The economics of museums", in Ginsburgh, V.A. and Throsby, D. (Eds), Handbook of the Economics of Art and Culture, Vol. 1, Elsevier, Amsterdam, pp. 1017-1047.

Goulding, C. (2006), "The museum environment and visitor experience", European Journal of Marketing, Vol. 34 Nos 3/4, pp. 261-278.

Hair, J.F., Black, W.C., Babin, B.J. and Anderson, R.E. (2010), Multivariate data analysis, 7th ed., Pearson Education Limited. 


\section{JHASS 2,3}

Hair, J.F., Jr, Hult, G.T.M., Ringle, C. and Sarstedt, M. (2014), A Primer on Partial Least Squares Structural Equation Modeling (PLS-SEM), Sage publications.

Hair, J.F., Jr, Hult, G.T.M., Ringle, C. and Sarstedt, M. (2016), A Primer on Partial Least Squares Structural Equation Modeling (PLS-SEM), 2nd ed., Sage publications.

Hair, J.F., Ringle, C.M. and Sarstedt, M. (2011), "PLS-SEM: indeed a silver bullet”, Journal of Marketing Theory and Practice, Vol. 19 No. 2, pp. 139-152.

Hair, J., Sarstedt, M., Ringle, C. and Mena, J. (2012), "An assessment of the use of partial least squares structural equation modelling in marketing research", Journal of the Academy of Marketing Science, Vol. 40 No. 3, pp. 414-433.

Heidenreich, M. and Plaza, B. (2015), "Renewal through culture, the role of museums in the renewal of industrial regions in Europe”, European Planning Studies, Vol. 23 No. 8, pp. 1441-1445.

Henseler, J., Ringle, C. and Sarstedt, M. (2015), "A new criterion for assessing discriminant validity in variance-based SEM", Journal of the Academy of Marketing Science, Vol. 43 No. 1, pp. 115-135.

Hooper-Greenhill, E. (1992), Museums and the Shaping of Knowledge, Routledge, London.

Hosany, S. and Prayag, G. (2013), "Patterns of tourists' emotional responses, satisfaction, and intention to recommend", Journal of Business Research, Vol. 66 No. 6, p. 732.

ICOM (2007), "Museum definition", available at:http://icom.museum/who-we-are/the-vision/museumdefinition.html (accessed June 2019).

Jin, N., Lee, S. and Lee, H. (2013), "The effect of experience quality on perceived value, satisfaction, image and behavioral intention of water park patrons: new versus repeat visitors", International Journal of Tourism Research, Vol. 17 No. 1, pp. 82-95.

Kang, M. and Gretzel, V. (2012), "Effects of podcast tours on tourist experiences in a national park", Tourism Management, Vol. 33 No. 2, pp. 440-455.

Kim, K., Hallab, Z. and Kim, J.N. (2012), "The moderating effect of travel experience in a destination on the relationship between the destination image and the intention to revisit", Journal of Hospitality Marketing and Management, Vol. 21 No. 5, pp. 486-505.

Kim, S., Holland, S. and Han, H. (2012), "A structural model for examining how destination image, perceived value and service quality affect destination loyalty: a case study of Orlando", International Journal of Tourism Research, Vol. 15 No. 4, pp. 313-328.

Kline, R.B. (2015), Principles and Practice of Structural Equation Modeling, Guilford press.

Li, B. (2018), "The influence of brand experience on people's revisit and purchase intention in the context of China's museum”, American Journal of Industrial and Business Management, Vol. 8 No. 3, pp. 563-578.

Liu, S. and Idris, M. (2018), "Constructing a framework of user experience for museum based on gamification and service design, EDP sciences and economy realms", Journal of Applied Business Research, Vol. 31 No. 2, p. 4.

Lu, L., Chi, C.G. and Liu, Y. (2015), "Authenticity, involvement, and image: evaluating tourist experiences at historic districts", Tourism Management, Vol. 50, pp. 85-96, available at: http:// Elsevier.com (accessed August 2018).

Maher, J., Clark, J. and Motely, D. (2011), "Measuring museum service quality in relationship to visitor membership: the case study of children's museum”, International Journal of Arts Management, Vol. 13 No. 2, pp. 29-42.

Martella, C., Miraglia, A., Frost, J., Cattani, M. and van Steen, M. (2017), "Visualizing, clustering, and predicting the behavior of museum visitors", Pervasive and Mobile Computing, Vol. 38, pp. 430-443.

Martin-Ruiz, D., Castellanos-Verdugo, M. and Oviedo-Garcia, M. (2010), “A visitor's evaluation index for a visit to an archeological site", Tourism Management, Vol. 31 No. 5, pp. 590-596.

Mei, X.Y. (2007), "Boring and expensive: the challenge of developing experience based tourism in the inland region. Norway", Tourism Management Perspectives, Vol. 12, pp. 71-80. 
Ozel, C. and Kozak, N. (2012), "Motive based segmentation of cultural tourism market: a study of Turkish domestic tourists", Journal of Quality Assurance in Hospitality and Tourism, Vol. 13 No. 3, pp. 165-186.

Pallant, J. (2011), "SPSS survival manual: a step by step guide to data analysis using SPSS", Crows Nest, Allen and Unwin, New South Wales.

Parasuraman, A., Zeithaml, V.A. and Berry, L.L. (1988), "SERVQUAL: a multiple-item scale for measuring consumer perceptions of service quality", Journal of Retailing, Vol. 64 No. 1, pp. $12-40$.

Prayag, G. and Ryan, C. (2012), "Antecedents of tourists loyalty to Mauritius: the rule and influence of

Application on the Grand Egyptian Museum destination image, place attachment, personal involvement and satisfaction”, Journal of Travel Research, Vol. 51 No. 3, pp. 342-356.

Rentschler, R. and Gilmore, A. (2002), "Museums: discovering services marketing", International Journal of Arts Management, Vol. 32 No. 1, pp. 62-72.

Ringle, C.M., Wende, S. and Becker, J.-M. (2015), Smart PLS 3, Smart PLS GmbH, Boenningstedt, available at: www.smartpls.com (accessed August 2018).

Sheng, C. and Chen, M. (2012), "A study of experience expectations of museum visitors", Tourism Management, Vol. 33 No. 1, pp. 53-60.

Shmueli, G., Sarstedt, M., Hair, J.F., Cheah, J.H., Ting, H., Vaithilingam, S. and Ringle, C.M. (2019), "Predictive model assessment in PLS-SEM: guidelines for using PLS predict", European Journal of Marketing, Vol. 53 No. 11, pp. 2322-2347, doi: 10.11 08/EJM-02-2019-0189.

Stern, E. and Krakover, S. (1993), "The formation of a composite urban image", Geographical Analysis, Vol. 25 No. 2, pp. 130-146.

Su, Y. and Teng, W. (2018), "Contemplating museums' service failure: extracting the service quality dimensions of museums from negative on-line reviews", Tourism Management, Vol. 69, p. 215.

Tan, W.K. (2016), "Repeat visitation: a study from the perspective of leisure constraint, tourist experience, destination images and experimental familiarity", Journal of Destination Marketing and Management, Vol. 6 No. 3, pp. 233-242, doi: 10.1016/2016.04.003 (accessed August 2018).

Usakli, A. and Kucukergin, K.G. (2018), "Using partial least squares structural equation modeling in hospitality and tourism: do researchers follow practical guidelines?", International Journal of Contemporary Hospitality Management, Vol. 30 No. 11, pp. 3462-3512.

Wang, W., Chen, J.S., Fan, L. and Lu, J. (2012), "Tourist experience and wetland parks: a case of Zhejiang, China”, Annals of Tourism Research, Vol. 39 No. 4, pp. 1763-1778.

Wang, C. and Hsu, M.K. (2010), "The relationships of destination image, satisfaction and behavioral intentions: an integrated model", Journal of Travel and Tourism Marketing, Vol. 27 No. 8, pp. 829-843.

Young-Joo, A. Wei-Jue, H. Norman, W. Hallo, J. and McGehee, N. (2016), "If you build it, they will come: relationship between attraction features and intention to visit", Travel and Tourism Research Association: Advancing Tourism Research Globally, 30, available at: https://scholarworks.umass. edu/ttra/2012/Oral/30

\section{Further reading}

Bates, S. and Ferri, A.J. (2010), "What's entertainment? Notes toward a definition", Studies in Popular Culture, Vol. 33 No. 1, pp. 1-20.

Bonn, M.A., Joseph-Mathews, S.M., Dai, M., Hayes, S. and Cave, J. (2008), "Heritage/cultural attraction atmospherics: creating the right environment for the heritage/cultural visitor", Journal of Travel Research, Vol. 45 No. 3, pp. 345-354.

Castro, C.B., Amano, E. and Ruiz, D. (2007), "The influence of market heterogeneity on the relationship between destination's image and tourists, future behavior", Tourism Management, Vol. 28 No. 1, pp. 175-187. 
JHASS
2,3

Chen, C.F. (2008), "Investigating structural relationship between service quality, perceived value, satisfaction, and behavioral intentions for air passengers: evidence from Taiwan", Transportation Research PART a: Policy and Practice, Vol. 42 No. 4, pp. 709-717.

Echtner, C.M. and Ritchie, J.R. (1993), "The measurement of destination image: an empirical assessment”, Journal of Travel Research, Vol. 31 No. 4, pp. 3-13.

Field, A. (2009), Discovering Statistics Using SPSS, Sage publications.

Getz, D. (2008), "Event tourism: definition, evolution and research", Tourism Management, Vol. 29 No. 3, pp. 403-428.

Grand Egyptian Museum “Grand Egyptian Museum website”, available at:http://gem.gov.eg (accessed August 2018).

Hair, J.F., Risher, J.J., Sarstedt, M. and Ringle, C.M. (2019), "When to use and how to report the results of PLS-SEM”, European Business Review, Vol. 31 No. 1, pp. 2-24.

Jordan, P.J. and Troth, A.C. (2019), "Common method bias in applied settings: the dilemma of researching in organizations", Australian Journal of Management, Vol. 45 No. 1, pp. 3-14, doi: 10.1177/0312896219871976. (accessed August 2018).

Kamal, M. and Pramanik, S.A. (2016), "Identifying factors influencing visitors to visit museums in Bangladesh and setting marketing strategies for museums", Journal of Business and Management, Vol. 17 No. 10, pp. 85-92.

Old Egyptian Museum "Old Egyptian museum website”, available at:http://art-for-a-change.com/blog/ 2011/02/the-museum-at-the-center-of-egypts-revolution.html (accessed August 2018).

Osborne, J.W. (2015), “What is rotating in exploratory factor analysis?' practical assessment”, Research and Evaluation, Vol. 20 No. 2, pp. 1-7.

Paswan, A.K. and Troy, A. (2004), "Non-profit organization and membership motivation: an exploration in the museum industry", Journal of Marketing Theory and Practice, Vol. 12 No. 2, pp. 1-15.

Podsakoff, P.M., MacKenzie, S.B., Lee, J.Y. and Podsakoff, N.P. (2003), "Common method biases in behavioral research: a critical review of the literature and recommended remedies", Journal of Applied Psychology, Vol. 88 No. 5, pp. 879.

Polit, D.F. and Beck, C.T. (2010), "Generalization in quantitative and qualitative research: myths and strategies", International Journal of Nursing Studies, Vol. 47 No. 11, pp. 1451-1458.

Thyne, M. (2000), "The importance of values research for nonprofit organizations: the motivation based values of museum visitors", International Journal of Nonprofit and Voluntary Sector Marketing, Vol. 6 No. 2, pp. 116-130.

Vaismoradi, M., Turunen, H. and Bondas, T. (2013), "Content analysis and thematic analysis: implications for conducting a qualitative descriptive study", Nursing and Health Sciences, Vol. 15 No. 3, pp. 398-405.

Zhang, H., Fu, X., Cai, L. and Lu, L. (2014), "Destination image and tourist loyalty: a meta-analysis", Tourism Management, Vol. 40, pp. 213-223, doi: 10.1016/j.tourman.2013.06.006.

\section{About the author}

Dr. Samia Adly Hanna El Sheikh (PhD) FHEA is a lecturer of Marketing and Business Administration in the faculty of Management Sciences, October University for Modern Sciences and Arts (MSA), Egypt, which is validated by University of Greenwich. She is also a fellow of the Higher Education Academy UK and successfully completed Post Graduate certificate in Higher Education from University of Greenwich UK. Samia Adly Hanna El Sheikh can be contacted at: selsheikh@msa.eun.eg

For instructions on how to order reprints of this article, please visit our website:

www.emeraldgrouppublishing.com/licensing/reprints.htm

Or contact us for further details: permissions@emeraldinsight.com 